\title{
Resenha de A arte queer do fracasso, de Jack Halberstam
}

Adriana Azevedo ${ }^{1}$

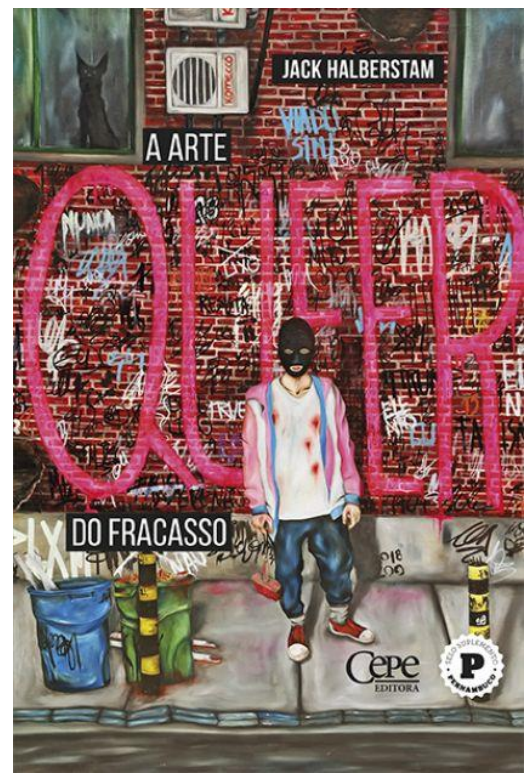

Resenha

Halberstam, Jack. A arte queer do fracasso. Trad. Bhuvi Libanio. Cepe Editora, 2020, 258 p.

\footnotetext{
1 Doutora pelo Programa de Literatura, Cultura e Contemporaneidade da Pontifícia Universidade Católica do Rio de Janeiro (PUC-Rio), com passagem pela Université de Lille 3 sob orientação de MarieHélene Sam Bourcier, e pesquisadora de pós-doutorado FAPERJ/PUC-Rio. Foi uma das idealizadoras do evento cultural Isoporzinho das Sapatão (RJ) e do livro Que o dedo atravesse a cidade, que o dedo perfure os matadouros (2018). Atualmente, está à frente do projeto de comunicação digital @escutafeminista e é uma das criadoras e editoras da editora independente Filipa, dedicada à publicação de contos, poemas e ensaios de pessoas LBTQI+.

Email: adrianapfa3@gmail.com
} 
Em 2020, a Companhia Editora de Pernambuco (Cepe editora) nos ofertou a tradução de $A$ arte queer do fracasso, de Jack Halberstam, um marco nos estudos queer, quase dez anos depois do lançamento do original, em inglês (The Queer Art of Faillure Duke University Press; edição de 12 agosto 2011 - de quando Halberstam ainda assinava como Judith Halberstam). Por conta das conturbações e das crises que atravessamos, infelizmente, o livro não fez tanto barulho quanto deveria, já que o autor precisou cancelar sua visita ao Brasil e os debates que aconteceriam em livrarias, como a Blooks, do Rio de Janeiro, em decorrência da pandemia do Covid-19. O livro, no entanto, se manifesta como uma leitura necessária e incontornável no campo da teoria queer e feminismos.

$A$ arte queer do fracasso é, conforme a descrição do próprio autor em sua introdução, "um passeio fora do confinamento do saber convencional e dentro de territórios não regulamentados do fracasso, da perda e do 'inadequar-se', [que] precisa fazer um longo desvio para evitar disciplinas e caminhos habituais do pensamento"

(Halberstam, 2020: 28). É uma construção de um pensamento que parte da perda como potência, e do fracasso como lugar constitutivo e frutífero, através de uma perspectiva que se esquiva do otimismo neoliberal - que se manifesta em "positivismos tóxicos" na cultura contemporânea -, e da chamada "alta teoria". O campo metodológico do autor é uma via alternativa, a chamada "baixa" teoria, inspirada no pensamento de Stuart Hall, que parte da cultura popular, dos desenhos animados da Pixar, de filmes desviantes, de conceitos não-canônicos, para situar o leitor em um campo de saber de fracassados e inadaptáveis.

Nos primeiros três capítulos, o autor se atém ao conceito de fracasso que quer abordar, mas não sem antes atravessar o que há de disruptivo na negatividade do fracasso, sem medo de se afundar nas emoções difíceis, nas perdas, num lugar sombrio. O fracasso como um lugar negativo, mas em sua importância vital. O seu interesse é em como esses lugares que são considerados impotentes - em sua possibilidade ambígua -, a uma lógica ocidental e ao heterocapitalismo, podem ser territórios conceituais e de vida que nos endereçam a possibilidades de saber insubmissas ao campo hegemônico do pensamento. No capítulo 4, Halberstam aborda as relações entre masoquismo, passividade e feminilidade como lugares não ativos e que possuem estreita relação com esse lugar não-produtivo, que reverte a lógica neoliberal de constituição da vida. No capítulo 5 é abordada a forma como gays e lésbicas podem colaborar com regimes políticos conservadores, dando o exemplo de Radclyffe Hall e outras mulheres masculinas que apoiavam movimentos fascistas na Inglaterra e eram abertamente antissemitas. No sexto e último capítulo, ele explora filmes de animação e as suas narrativas de fuga da lógica heteropatriarcal e especista, com enfoque especial em $O$ 
fantástico senhor raposo (2009), animação de Wes Anderson, como exemplo de animações queer, onde personagens têm filhos efeminados, rabos destacáveis, e sinalizam "a importância de simplesmente sobreviver para todas as almas selvagens que os fazendeiros, os professores, os pregadores e os políticos gostariam de enterrar vivas" (Halberstam, 2020: 244).

Halberstam nos ensina, em $A$ arte queer do fracasso, a ativarmos o nosso desejo básico de vivermos a vida de outra forma. Partindo da baixa teoria e de um mapeamento de formas de pensamento e de fazer teóricos que fujam à hegemonia (como na criativa análise do desenho animado Bob Esponja que abre o livro), ele encena em seu texto 0 que José Esteban Muñoz chamou de "utopias concretas" em seu livro Cruising Utopia: The Then and There of Queer Futurity, de 2009. As vidas queer têm a potência de construir outros mundos por se recusarem a formas de sucesso que são reconhecidas a maturidade, como acúmulo de riqueza e capacidade reprodutiva. O campo das animações infantis é um campo de pensamento para o autor por ele reconhecer a infância como um resgate de uma vida anárquica e indisciplinada, que precede à vida adulta de disciplina e controle.

De forma pertinentemente crítica, ele nos provoca enquanto reflete acerca do "pensamento positivo" - modo de vida amplamente vendido contemporaneamente através das redes sociais - como uma "ilusão em massa" norte-americana. 0 pensamento positivo seria uma forma de reconhecer apenas o sucesso como uma forma de vida de pessoas boas, e o fracasso como consequência de um comportamento desordenado e, por isso, ruim e digno de vidas que saíram do eixo da humanidade. A partir daí, o fracasso se torna um local de possibilidade para "um novo tipo de otimismo" que, segundo o autor, não seria

um otimismo que depende do pensamento positivo como mecanismo explicativo da ordem social, nem um que insiste no lado bom a todo custo; em vez disso, esse é um raio de sol singelo que produz sombra e luz em iguais medidas e que sabe que o significado de um depende do significado do outro. (Halberstam, 2020: 25)

Halberstam inicia seu livro se perguntando qual é a saída para o dualismo entre uma resignação cínica e o otimismo inocente. O que ele propõe é um entre-lugar, um inbetween. Esse entre-lugar faz parte de um novo modo de relação que ele propõe não só com o pensamento ou a política, mas com a vida, a cultura, o conhecimento e o prazer. O que é elaborado, é o que chama "low-theory". Essa "baixa teoria" está localizada "entre alta e baixa cultura, alta e baixa teoria, cultura popular e conhecimento 
esotérico, a fim de empurrar através das divisões entre vida e arte, prática e teoria, pensar e fazer, e para dentro de uma forma mais caótica de saber e des-saber".

O gesto de se forçar nesse in-between, nesse entre-lugar, aplica-se à postura perante ao binarismo entre o otimismo inocente e a resignação cínica, sobre o qual citei há pouco. Para Halberstam, é necessário pensar em vidas que se colocam fora do nosso entendimento convencional de sucesso, ideal para uma sociedade capitalista e heteronormativa, que equaliza formas de maturidade sexual com acumulo de riquezas. No entanto, "para os queers, a falha pode ser um estilo", e esse estilo que falha, esse modo de vida que por si só pode ser entendido como uma falha nos provém a oportunidade para usar afetos negativos para fazer um buraco na tóxica positividade contemporânea.

É necessário repensar o que é positivo e negativo, antes de tudo - para falarmos desses modos de vida queers e para que esse buraco na positividade tóxica ocorra de fato. Precisamos nos deslocar até esse in-between, transvalorando o positivo e 0 negativo, o acerto e a falha. $O$ fracasso de Halberstam tem direta relação com o que ele está conceituando como otimismo, por mais contraditório que pareça à nossa lógica metafísica instituída, e direta relação com o que tento aqui pensar e elaborar sobre esse conceito. O que as vidas queers carregam como falha produz vulnerabilidades, já que a falha é justamente em relação a todo esse estilo normativo e capitalista dominante. $O$ jovem que falha às regras heteronormativas da família tradicional, por exemplo, sofre, em sem números de casos, violências por falhar. Por falhar ser seu estilo. Mas as vidas resistem. Resistir é o que resta. Há uma esperança vital, a vontade de potência, que dá à falha queer o seu caráter mais produtivo, criativo, mesmo ela produzindo uma ferida. Só que essa ferida é uma abertura que é ao mesmo tempo dor e possibilidade. Possibilidade de algo novo, de um porvir.

Os filmes de animação se tornam então, o corpus de análise de Halberstam, porque eles têm a capacidade de ensinar às crianças (e a nós, adultos que não nos ordenamos por completo no modo de vida cisheterocapitalista) acerca da revolta através dessa existência do "perdedor". Suas narrativas navegam constantemente no domínio do fracasso, e o são justamente porque a infância é uma temporalidade do estranhamento, da criação, da imaginação de mundos incríveis e poéticos, e é o tempo em que nossos corpos ainda não foram normalizados pelos paradigmas que constituem um crescimento bem-sucedido.

A arte queer do fracasso é parte de um acervo fundamental para entender o pensamento queer contemporâneo, mas também é uma ferramenta teórica útil para as humanidades de forma ampla. Halberstam é um exemplo de como a teoria queer não é um campo do conhecimento para sujeitos específicos e implicados somente nas 
vivências queer, mas seu pensamento se manifesta como um abalo nas teorias interessadas em aliar vida, política, teoria e escrita. Ao contrário das práticas de conhecimento supostamente sem autoria, sem um saber localizado, que têm a pretensão de falar a partir de e para um sujeito universal abstrato (o homem cis-heterobranco), neste caso, trata-se de um autor que assume sua localização do saber ao mesmo tempo em que acessa acervos diversos, que abrem reflexões amplas, e aborda questões econômicas, raciais, de gênero e sexualidade como categorias dignas de análise.

Jack Halberstam é autor de outros livros que caminham por gestos similares, como Female Masculinity (1998), que faz uma rara reflexão das masculinidades não hegemônicas a partir das vivências butch/femme, das dykes, da cultura drag king e das transmasculinidades. Além de ter publicado também: Skin Shows: Gothic Horror and the Technology of Monsters (1995), In a Queer Time and Place: Transgender Bodies, Subcultural Lives (2005), Gaga Feminism (2012), Trans*: A Quick and Quirky Account of Gender Variability (2018) e o mais recente lançamento Wild Things: The Disorder of Desire (2020). Ele é professor titular do Departamento de Inglês e Literatura Comparada e do Instituto de Pesquisa sobre Mulheres, Gênero e Sexualidade na Universidade de Columbia, e já foi professor de Estudos Americanos e Etnicidade, Estudos de Gênero e Literatura Comparada e Diretor do Centro de Pesquisa Feminista da University of Southern California (USC), além disso, no início de sua carreira atuou também como Professor Associado do Departamento de Literatura da Universidade da Califórnia, em San Diego.

Tive a oportunidade de ser alune de Halberstam em duas ocasiões, em uma masterclass que ele ministrou em 2011, na UFRJ, durante o congresso internacional Queering Paradigms e, posteriormente, em um curso que dividiu com Paul B. Preciado em 2014, no Pompidou, em Paris, intitulado We have never been queer (Nós nunca fomos queers). Seu pensamento, no entanto, já havia me fisgado um pouco antes, em 2010, quando me deparei com a primeira cópia de um livro seu, na Argentina, Masculinidad Femenina, uma tradução espanhola. Sua produção teórica vasta, que nos oferta questões urgentes para enfrentarmos os desafios do contemporâneo, e seu modo de pensar a partir de um acervo não-convencional, são os motivos para que suas obras se tornem cada vez mais traduzidas e disponibilizadas para o público brasileiro. 